\title{
Listeria monocytogenes Growth Kinetics in Milkshakes Made from Naturally and Artificially Contaminated Ice Cream
}

\author{
Joelle K. Salazar1, Vriddi M. Bathija2, Christina K. Carstens' ${ }^{1}$, Sartaj S. Narula², \\ Arlette Shazer ${ }^{1}$, Diana Stewart ${ }^{1}$ and Mary Lou Tortorello ${ }^{1 *}$ \\ ${ }^{1}$ Division of Food Processing Science and Technology, U.S. Food and Drug Administration, Bedford Park, IL, United States, \\ ${ }^{2}$ Institute for Food Safety and Health, Illinois Institute of Technology, Bedford Park, IL. United States
}

\section{OPEN ACCESS}

Edited by:

Jean-Christophe Augustin,

École Nationale Vétérinaire d'Alfort,

France

Reviewed by:

Antonio Valero,

Universidad de Córdoba, Spain Beatrix Stessl,

Veterinärmedizinische Universität

Wien, Austria

${ }^{*}$ Correspondence:

Mary Lou Tortorello mary.tortorello@fda.hhs.gov

Specialty section: This article was submitted to

Food Microbiology,

a section of the journal

Frontiers in Microbiology

Received: 02 October 2017 Accepted: 10 January 2018

Published: 24 January 2018

Citation:

Salazar JK, Bathija VM, Carstens CK, Narula SS, Shazer A

Stewart D and Tortorello ML (2018) Listeria monocytogenes Growth Kinetics in Milkshakes Made from

Naturally and Artificially Contaminated Ice Cream. Front. Microbiol. 9:62. doi: 10.3389/fmicb.2018.00062
This study assessed the growth of Listeria monocytogenes in milkshakes made using the process-contaminated ice cream associated with a listeriosis outbreak in comparison to milkshakes made with artificially contaminated ice cream. For all temperatures, growth kinetics including growth rates, lag phases, maximum populations, and population increases were determined for the naturally and artificially derived contaminants at $5,10,15$, and $25^{\circ} \mathrm{C}$ storage for $144 \mathrm{~h}$. The artificially inoculated L. monocytogenes presented lower growth rates and shorter lag phases than the naturally contaminated populations at all temperatures except for $5^{\circ} \mathrm{C}$, where the reverse was observed. At $25^{\circ} \mathrm{C}$, lag phases of the naturally and artificially contaminated L. monocytogenes were 11.6 and $7.8 \mathrm{~h}$, respectively. The highest increase in population was observed for the artificially inoculated pathogen at $15^{\circ} \mathrm{C}$ after $96 \mathrm{~h}(6.16 \mathrm{log}$ $\mathrm{CFU} / \mathrm{mL}$ ) of storage. Growth models for both contamination states in milkshakes were determined. In addition, this study evaluated the antimicrobial effectiveness of flavoring agents, including strawberry, chocolate and mint, on the growth of the pathogen in milkshakes during $10^{\circ} \mathrm{C}$ storage. All flavor additions resulted in decreased growth rates of $L$. monocytogenes for both contamination states. The addition of chocolate and mint flavoring also resulted in significantly longer lag phases for both contamination states. This study provides insight into the differences in growth between naturally and artificially contaminated $L$. monocytogenes in a food product.

Keywords: ice cream, Listeria monocytogenes, growth kinetics, growth model, natural contamination

\section{INTRODUCTION}

Listeria monocytogenes is commonly present in bulk tank milk (Jackson et al., 2012) and has long been recognized to be able to survive in facilities where dairy products are processed, including frozen dairy products such as ice cream. A listeriosis outbreak, which occurred in the United States between the years 2010 and 2015 and resulted in 10 total cases, 100\% hospitalization rate, and three deaths, was linked to the consumption of ice cream products, which became contaminated post-pasteurization by L. monocytogenes present in the processing environment (CDC, 2015; FDA, 2015). Four of the cases resulted from consuming milkshakes prepared from the contaminated ice cream at a healthcare facility. The ice cream was packaged into single-serving units, and it has been 
determined that approximately $92 \%$ of these samples were contaminated with at least two strains of L. monocytogenes at a nearly uniform level of less than 20 most probable number (MPN)/g (Chen, 2015; Chen et al., 2016b, 2017).

The availability of uniformly and naturally contaminated samples of the ice cream product provided an unusual opportunity to study the behavior of L. monocytogenes contaminants in a realistic condition. Challenge studies are generally conducted using artificial inoculation of food products with a target pathogen. Naturally contaminated food products are rarely available for research purposes because they are often destroyed when a recall or outbreak occurs. However, a few published reports do exist in which the behavior of L. monocytogenes was assessed in naturally contaminated foods, and these included smoked salmon (Cortesi et al., 1997; Dalgaard and Jørgensen, 1998; Lappi et al., 2004; Beaufort et al., 2007), seafood (Jørgensen and Huss, 1998; Mejlholm et al., 2015), chorizo (Encinas et al., 1999) and raw meat (Farber and Daley, 1994; Ryser et al., 1996). Only one study involved a naturally contaminated dairy product, i.e., the ice cream associated with the 2010-2015 listeriosis outbreak (Chen et al., 2016a).

It is not clear how pathogen growth and survival data might differ between artificial and natural contaminants when used in challenge studies. Any differences could be usefully considered if the data were to be used for risk assessment purposes. In this study, milkshakes were made using both naturally and artificially contaminated ice cream products to determine whether the behavior of the pathogen would differ between the two modes of contamination. Storage temperatures of $5,10,15$, and $25^{\circ} \mathrm{C}$ were chosen to simulate a range of temperature holding and abuse conditions. For example, in the case of the recent outbreak, milkshakes might have been previously made and then stored under refrigeration $\left(5^{\circ} \mathrm{C}\right)$ before being given to the patients; or they might have been left at room temperature $\left(25^{\circ} \mathrm{C}\right)$ and consumed at a later time. The inclusion of additional temperatures would allow a better understanding of the influence of temperature on the growth of both naturally and artificially contaminated L. monocytogenes. In addition, this study also aimed to determine the effect of flavoring agents, which have demonstrated antimicrobial activity (Puupponen-Pimiä et al., 2005; Nohynek et al., 2006; Lixandru et al., 2010; Akdemir Evrendilek, 2015), on the growth and survival of L. monocytogenes in the milkshakes. The comparison of L. monocytogenes behavior in flavored and unflavored milkshakes, made with naturally or artificially contaminated ice cream samples and storage at various temperatures, could help to determine the adequacy of laboratory studies conducted with artificially inoculated food samples for use in risk assessment via predictive modeling.

\section{MATERIALS AND METHODS}

\section{L. monocytogenes Strains and Culture Conditions}

Resistance to rifampicin $(100 \mu \mathrm{g} / \mathrm{mL})$ was selected in five L. monocytogenes strains: F2365 (serotype 4b, isolated from
Mexican soft cheese) (Linnan et al., 1988; Chen et al., 2016c), ScottA (serotype 4b, sequence type 290, isolated from milk) (Fleming et al., 1985; Briers et al., 2011), FSL R2-502 (serotype $1 / 2 \mathrm{~b}$, sequence type 3 , isolated from chocolate milk) (Dalton et al., 1997; Chen et al., 2016c), LS806 (serotype 4b, sequence type 1 , isolated from cheese), and JKS-1, a strain isolated from the process-contaminated ice cream associated with the listeriosis outbreak. The naturally contaminated L. monocytogenes found in the ice cream (including JKS-1) belong to sequence type 5, molecular serogroup IIb, and genetic lineage I (Chen et al., 2017). All strains were grown separately in Brain Heart Infusion (BHI, Becton Dickinson \& Co., Sparks, MD, United States) broth containing rifampicin at $37^{\circ} \mathrm{C}$ for $16-18 \mathrm{~h}$ with $150 \mathrm{rpm}$ shaking. A cocktail of F2365, Scott A, R2-502, and LS806 or JKS-1 by itself was used for artificial inoculation of ice cream.

\section{Artificial Inoculation of Naturally Contaminated Ice Cream}

The L. monocytogenes cultures were washed twice with Butterfield's phosphate buffer (BPB), $\mathrm{pH}$ 7.4, combined if used as a cocktail, and diluted to $4 \log \mathrm{CFU} / \mathrm{mL}$. Individual $80-\mathrm{g}$ ice cream product samples ("scoops"), which were naturally contaminated with approximately $10 \mathrm{MPN} / \mathrm{g}$ L. monocytogenes during manufacture (Chen, 2015), were divided into four groups (Figure 1): one group remained as naturally contaminated $(\mathrm{N})$, the second group was artificially contaminated with the four-strain cocktail (A), and the third group was artificially contaminated with JKS-1 (AJ). For groups A and AJ, $80 \mu \mathrm{L}$ of the cocktail or single strain was pipetted into the center of each ice cream scoop with a wide-orifice pipette tip, resulting in a final concentration of $10 \mathrm{CFU} / \mathrm{g}$. A subset of the artificially contaminated ice cream samples (A) was stored at $-20^{\circ} \mathrm{C}$ for 1.5 years (AC; cold-adapted artificially inoculated).

\section{Preparation of Milkshakes}

Milkshakes were prepared according to the recipe used at the outbreak-associated healthcare facility (Yi Chen, personal communication). Individual ice cream scoops (N, A, AJ, or AC; see Figure 1) were placed into sterile metal mixing cups and combined with $60 \mathrm{~mL}$ ultra-high temperature pasteurized (UHT) $1 \%$ milk. UHT milk was used to decrease background microbiota on agar plates. For milkshakes with flavoring agents ( $\mathrm{N}$ and $\mathrm{A}$; see Figure 1), commercial strawberry syrup $(15 \mathrm{~mL})$, chocolate syrup $(15 \mathrm{~mL})$, or mint extract $(2.5 \mathrm{~mL})$ was added. Samples were homogenized for $2 \mathrm{~min}$ at medium speed using a commercial Hamilton Beach HMD200 Drink Mixer (Hamilton Beach, Inc., Southern Pines, NC, United States) and then were transferred to $125 \mathrm{~mL}$ sterile polystyrene cups with lids. Milkshakes were stored at $5,10,15$, and $25^{\circ} \mathrm{C}$ (for $\mathrm{A}$ and $\mathrm{N}$; see Figure 1) or at 10 and $25^{\circ} \mathrm{C}$ (for $\mathrm{AJ}$ and $\mathrm{AC}$; see Figure 1) for 12, $24,48,72,96$, and $144 \mathrm{~h}$. For $25^{\circ} \mathrm{C}$, additional timepoints of 3 , 6, and $9 \mathrm{~h}$ were included. Four milkshake replicates were assessed for each group at each timepoint. Three independent experiments were conducted for $\mathrm{A}$ and $\mathrm{N}$ milkshakes and 


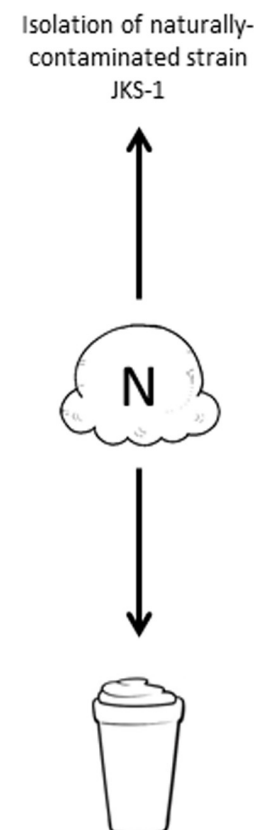

Storage at

$5,10,15$, and $25^{\circ} \mathrm{C}$
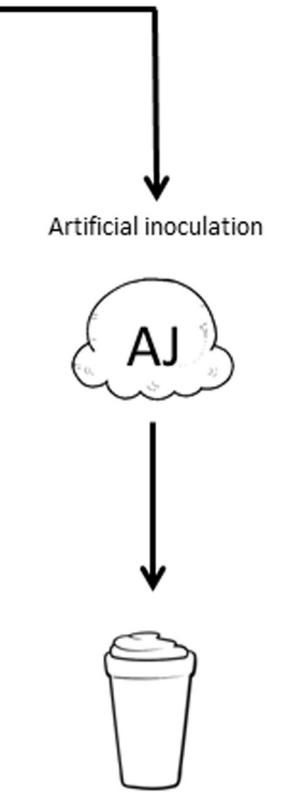

Storage at 10 and $25^{\circ} \mathrm{C}$

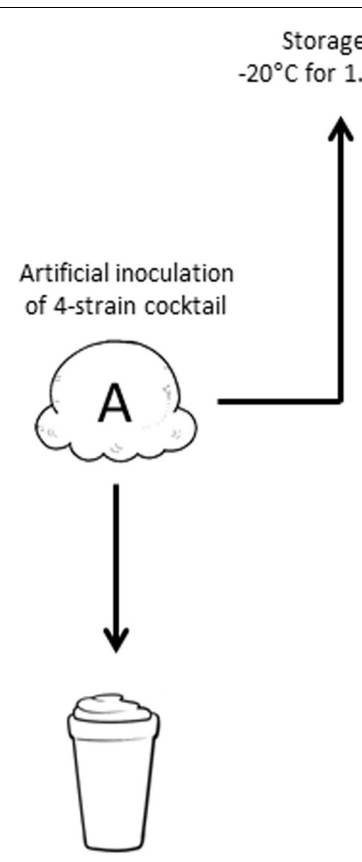

Storage at

$5,10,15$, and $25^{\circ} \mathrm{C}$

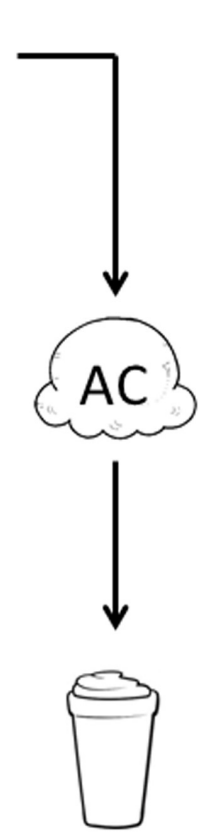

Storage at 10 and $25^{\circ} \mathrm{C}$

FIGURE 1 | The four contamination situations of L. monocytogenes utilized in this study. N, naturally contaminated; AJ, artificially contaminated JKS-1; A, artificially contaminated; AC, artificially contaminated 1.5 -year-cold-adapted.

two independent experiments were conducted for AJ and AC milkshakes.

\section{Enumeration of Naturally and Artificially Contaminated $L$. monocytogenes from Milkshakes}

At each timepoint, duplicate 40-g quantities of milkshake were each placed into a 1-L stomacher bag with $450 \mathrm{~mL}$ Buffered Listeria Enrichment Broth (BLEB, Becton Dickinson \& Co., Sparks, MD, United States). For artificially inoculated samples
(A, AJ, and AC milkshakes), rifampicin was added to the BLEB to a final concentration of $100 \mu \mathrm{g} / \mathrm{mL}$ to eliminate the population of natural L. monocytogenes contaminants. Samples were stomached for $1 \mathrm{~min}$ at $180 \mathrm{rpm}$ in a Seward 3500 stomacher (Seward Laboratory Systems Inc., Davie, FL, United States). The FDA Most Probable Number (MPN) method (Hitchins et al., 2016) was used to enumerate the low levels of L. monocytogenes. The MPN scheme included four levels of dilutions: 3 bags of $100 \mathrm{~mL}$ each, 5 tubes of $10 \mathrm{~mL}$ each, 8 tubes of $1 \mathrm{~mL}$ each, and 8 tubes of $0.1 \mathrm{~mL}$ each (Chen, 2015), resulting in final milkshake sample quantities of $8.2,0.82,0.082$, and $0.0082 \mathrm{~mL}$,

TABLE 1 | Growth kinetics of L. monocytogenes in milkshakes (A and N, see Figure 1) made from naturally and artificially contaminated ice cream and stored at different temperatures.

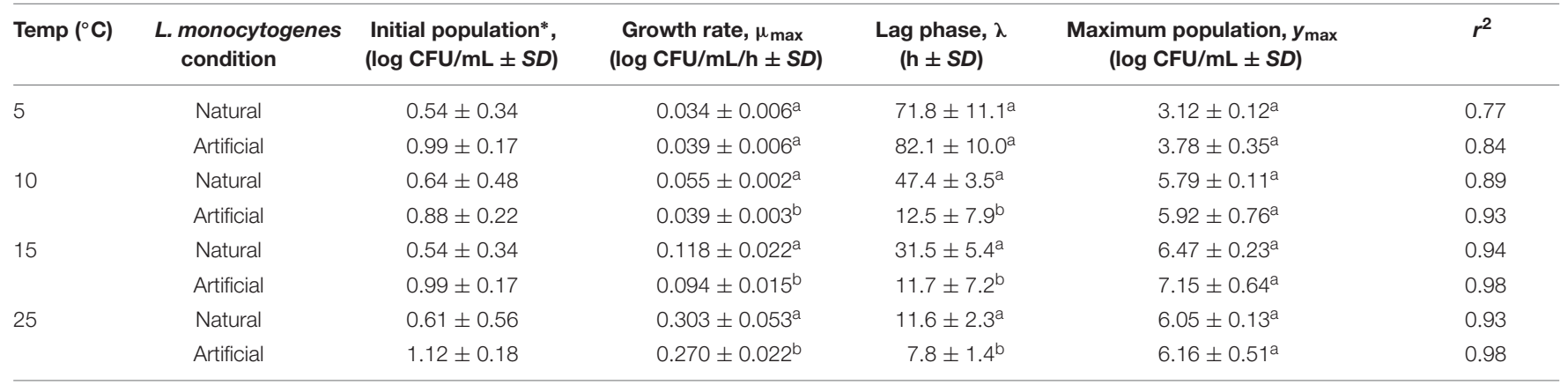

* Initial population refers to enumerated pathogen contamination immediately after mixing of milkshakes. SD, standard deviation. No significant differences between initial populations were observed. Different lowercase letters indicate significant difference $(P<0.05)$ between specific parameters for natural and artificial L. monocytogenes contamination in milkshakes stored at the same temperature. 
respectively. The MPN bags and tubes were incubated at $30^{\circ} \mathrm{C}$, with the addition of BLEB supplement (Oxoid Ltd., Hampshire, United Kingdom) after $4 \mathrm{~h}$ of incubation. After 24 and $48 \mathrm{~h}$ of incubation, all samples were streaked onto Brilliance Listeria agar (Oxoid) for determining the natural L. monocytogenes (N) and onto Plate Count Agar (Becton Dickinson \& Co., Sparks, MD, United States) supplemented with $100 \mu \mathrm{g} / \mathrm{mL}$ rifampicin for determining the artificial L. monocytogenes (A, AJ, and AC). L. monocytogenes MPN concentrations were calculated using the FDA Excel (Microsoft, Redmond, WA, United States) spreadsheet freely available at http://www.fda.gov/Food/Food ScienceResearch/LaboratoryMethods/ucm109656.htm. At timepoints where L. monocytogenes was above the limit of detection of the MPN scheme (approximately $253 \mathrm{MPN} / \mathrm{mL}$ ), the stomached samples were serially diluted and directly plated. All agar plates were incubated at $37^{\circ} \mathrm{C}$ for $48 \mathrm{~h}$.

\section{Predictive Primary and Secondary Modeling}

The DMFit version 3.0 (Institute of Food Research, Norwich, United Kingdom) Excel add-on from ComBase ${ }^{1}$ was used to model the maximum growth rates ( $\mu_{\max } ; \log \mathrm{CFU} / \mathrm{mL} / \mathrm{h}$ ), lag phases $(\lambda ; \mathrm{h})$, and maximum population densities $\left(y_{\max }\right.$; $\log \mathrm{CFU} / \mathrm{mL}$ ) of the naturally and artificially contaminated L. monocytogenes at each temperature, with or without flavoring addition, using the Baranyi model (Baranyi and Roberts, 1994). Secondary modeling of growth rate was determined using the Ratkowsky square root equation (eq. 1) (Ratkowsky et al., 1982). From the equation, a comparison of lag time with temperature can be determined (eq. 2). Parameters $b$ and $T_{\min }\left({ }^{\circ} \mathrm{C}\right)$ were computed for each model.

$$
\begin{gathered}
\sqrt{\mu_{\max }}=b\left(T-T_{\min }\right) \\
\ln (\lambda)=\ln \left[\frac{1}{\left(b\left(T-T_{\min }\right)\right)^{2}}\right]
\end{gathered}
$$

where $b$ is the regression coefficient, $T$ is temperature, and $T_{\min }$ is the theoretical minimum temperature below which microbial growth does not occur.

\section{Statistical Analysis}

Statistical analyses were evaluated using GraphPad Prism v 7.0 and GraphPad InStat v 3.0 (GraphPad Software, Inc., La Jolla, CA, United States). Tukey's adjusted one-way analysis of variance was utilized and a $P$ value less than 0.05 was considered significant.

\section{RESULTS}

\section{Growth Kinetics of L. monocytogenes in Milkshakes Made from Naturally and Artificially Contaminated Ice Cream}

Growth rates, lag phases, and maximum population densities were determined based on the model of Baranyi and Roberts

\footnotetext{
${ }^{1}$ www.combase.cc
}

(1994) using DMFit for both naturally and artificially contaminated L. monocytogenes in milkshakes during $144 \mathrm{~h}$ storage at four temperatures (Table 1). Maximum population's densities were also determined for both contamination states at all temperatures. Figure 2 depicts growth of the natural and artificial L. monocytogenes contamination states $(\mathrm{N}$ and $\mathrm{A}$, see Figure 1) in milkshakes during storage at 5 (Figures 2A,B), 10 (Figures 2C,D), 15 (Figures 2E,F), and $25^{\circ} \mathrm{C}$ (Figures 2G,H). At $5^{\circ} \mathrm{C}$, no significant differences were observed between the growth rates or lag phases of the naturally or artificially contaminated L. monocytogenes. An overall increase in population of approximately 2.58 and $2.79 \log \mathrm{CFU} / \mathrm{mL}$ was seen for the natural and artificial contamination states, respectively, after $144 \mathrm{~h}$ in milkshakes stored at $5^{\circ} \mathrm{C}$. At 10 , 15 , and $25^{\circ} \mathrm{C}$, the growth rates of the naturally contaminated L. monocytogenes were significantly higher than those of the artificially contaminated. The lag phases of the naturally contaminated pathogen were also significantly longer than the artificially contaminated at 10,15 , and $25^{\circ} \mathrm{C}$. However, the maximum attained populations of either state were not significantly different. At $10^{\circ} \mathrm{C}$, overall increases in populations of approximately 5.15 and $5.04 \log \mathrm{CFU} / \mathrm{mL}$ were observed for the natural and artificial contamination states, respectively, after $144 \mathrm{~h}$ storage. The highest population increases, approximately 5.93 and $6.16 \log \mathrm{CFU} / \mathrm{mL}$, were observed by the naturally and artificially contaminated pathogen at $15^{\circ} \mathrm{C}$ after only $96 \mathrm{~h}$ storage. The shortest lag phases overall at approximately 12 and $8 \mathrm{~h}$, were observed by the naturally and artificially contaminated L. monocytogenes at $25^{\circ} \mathrm{C}$, respectively.

For comparison, the naturally contaminating L. monocytogenes strain JKS-1, which was isolated from the ice cream, was artificially inoculated into the ice cream samples (AJ) for growth kinetics experiments in milkshakes. Results indicated that the 10 and $25^{\circ} \mathrm{C}$ growth rates of the four-strain cocktail $(\mathrm{A} ; 0.039 \pm 0.01$ and $0.270 \pm 0.02 \log \mathrm{CFU} / \mathrm{mL}$ per $\mathrm{h}$, respectively, see Table 1 ) and the JKS-1 naturally contaminating strain (AJ; $0.042 \pm 0.01$ and $0.275 \pm 0.05 \log \mathrm{CFU} / \mathrm{mL}$ per $h$, respectively) were not significantly different at each temperature. In addition, ice cream with 1.5-year-cold-adapted artificially contaminated L. monocytogenes (AC) was used to prepare milkshakes. The growth rates of the cold-adapted L. monocytogenes (AC) at 10 and $25^{\circ} \mathrm{C}$ were $0.035 \pm 0.01$ and $0.213 \pm 0.09 \log \mathrm{CFU} / \mathrm{mL}$ per $\mathrm{h}$, respectively. These growth rates were also not significantly different than those of the artificially inoculated L. monocytogenes (A) which was not coldadapted.

\section{Effect of Flavoring Agents on the Growth of $L$. monocytogenes in Naturally and Artificially Contaminated Ice Cream Milkshakes}

Growth kinetics parameters as determined in the flavoring study are listed in Table 2. All growth data for L. monocytogenes during storage at $10^{\circ} \mathrm{C}$ in milkshakes (A and $\mathrm{N}$, see Figure 1) with strawberry (Figures 3A,B), chocolate (Figures 3C,D), and mint flavorings are shown in Figures 3E,F. 

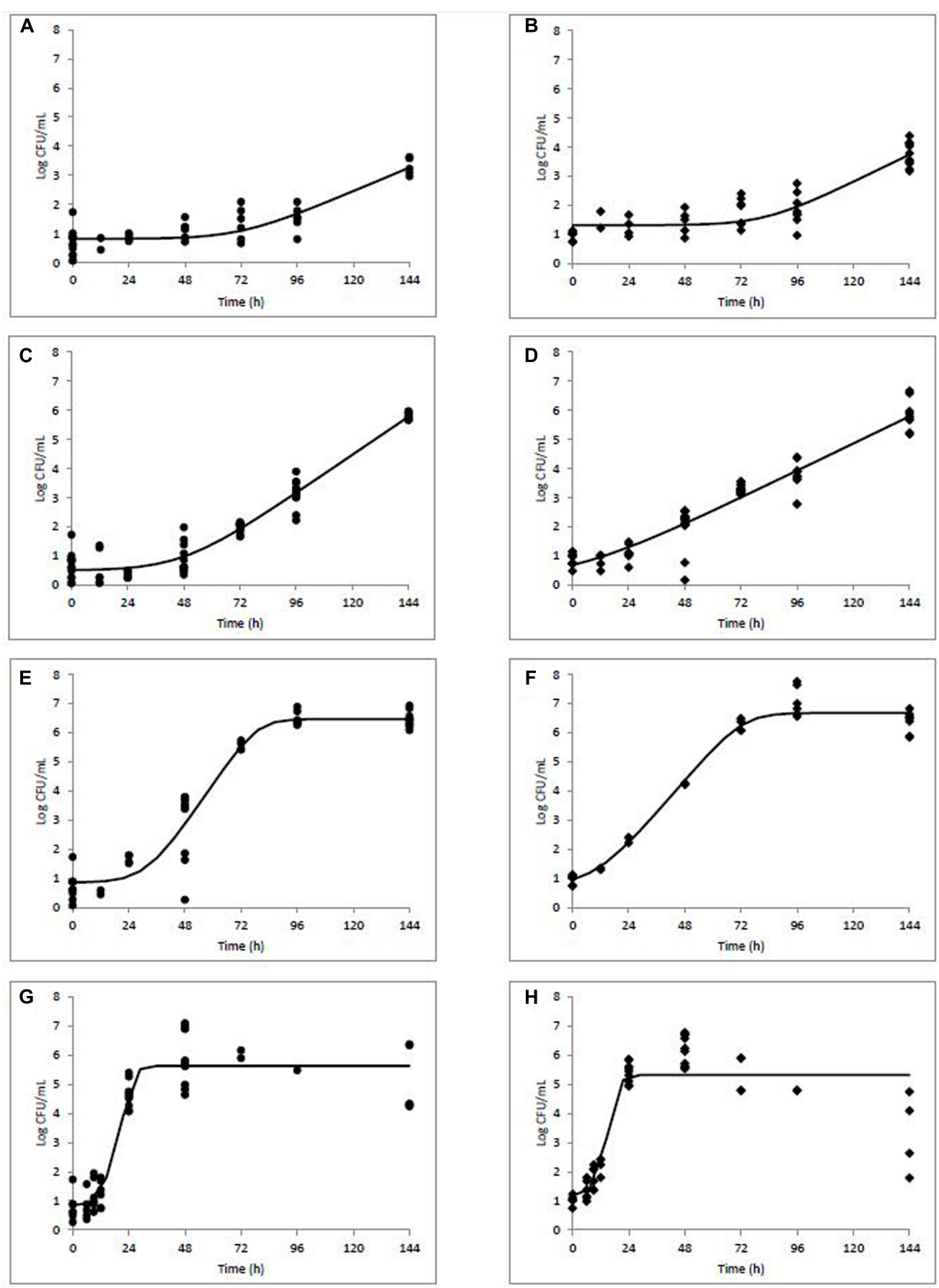

FIGURE 2 | Modeled growth of L. monocytogenes in milkshakes made from naturally and artificially contaminated ice cream stored at 5 (A,B), 10 (C,D), 15 (E,F), or $25^{\circ} \mathrm{C} \mathbf{( G , H )}$ for $144 \mathrm{~h}$. Data points represent CFU per mL of milkshake. Line represents modeled growth. Circles (A,C,E,G) are naturally contaminated and diamonds (B,D,F,H) are artificially contaminated L. monocytogenes populations.

In milkshakes flavored with strawberry ( $\mathrm{N}$ and $\mathrm{A}$ milkshakes), the naturally contaminated L. monocytogenes population had a significantly higher growth rate, yet significantly longer lag phase than its artificial counterpart, similar to what was observed in milkshakes without flavoring. No significant difference was determined between maximum attained populations by either pathogen contamination state in milkshakes with strawberry flavoring after $144 \mathrm{~h}$. An overall increase of approximately 4.88 and $4.94 \log \mathrm{CFU} / \mathrm{mL}$ in populations of the natural and artificial contamination states was observed in milkshakes with strawberry flavoring, respectively. 
TABLE 2 | Growth kinetics of L. monocytogenes at $10^{\circ} \mathrm{C}$ in milkshakes (A and N, see Figure 1) made from naturally and artificially contaminated ice cream and with different flavoring agents.

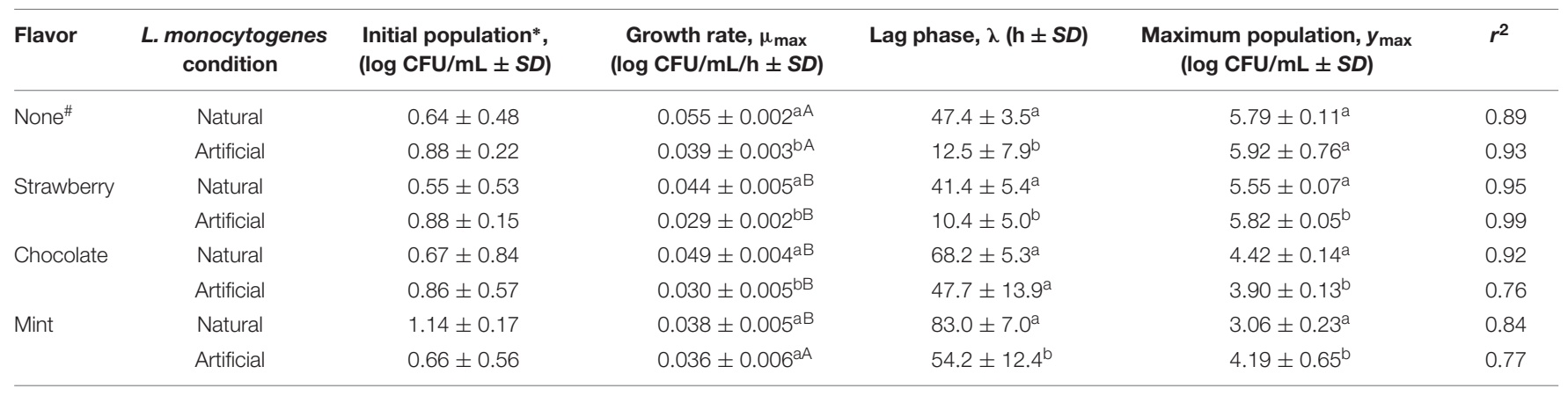

*Initial population refers to enumerated pathogen contamination immediately after mixing of milkshakes. "The $10^{\circ} \mathrm{C}$ storage data from Table 1 are repeated here for convenient comparison. SD, standard deviation. No significant differences between initial populations were observed. Different lowercase letters indicate significant difference $(P<0.05)$ between specific parameters for natural and artificial L. monocytogenes contamination in milkshakes made with the same flavoring agent. Different uppercase letters indicate significant difference $(P<0.05)$ between growth rates of naturally or artificially contaminated L. monocytogenes in milkshakes made with different flavoring agents.
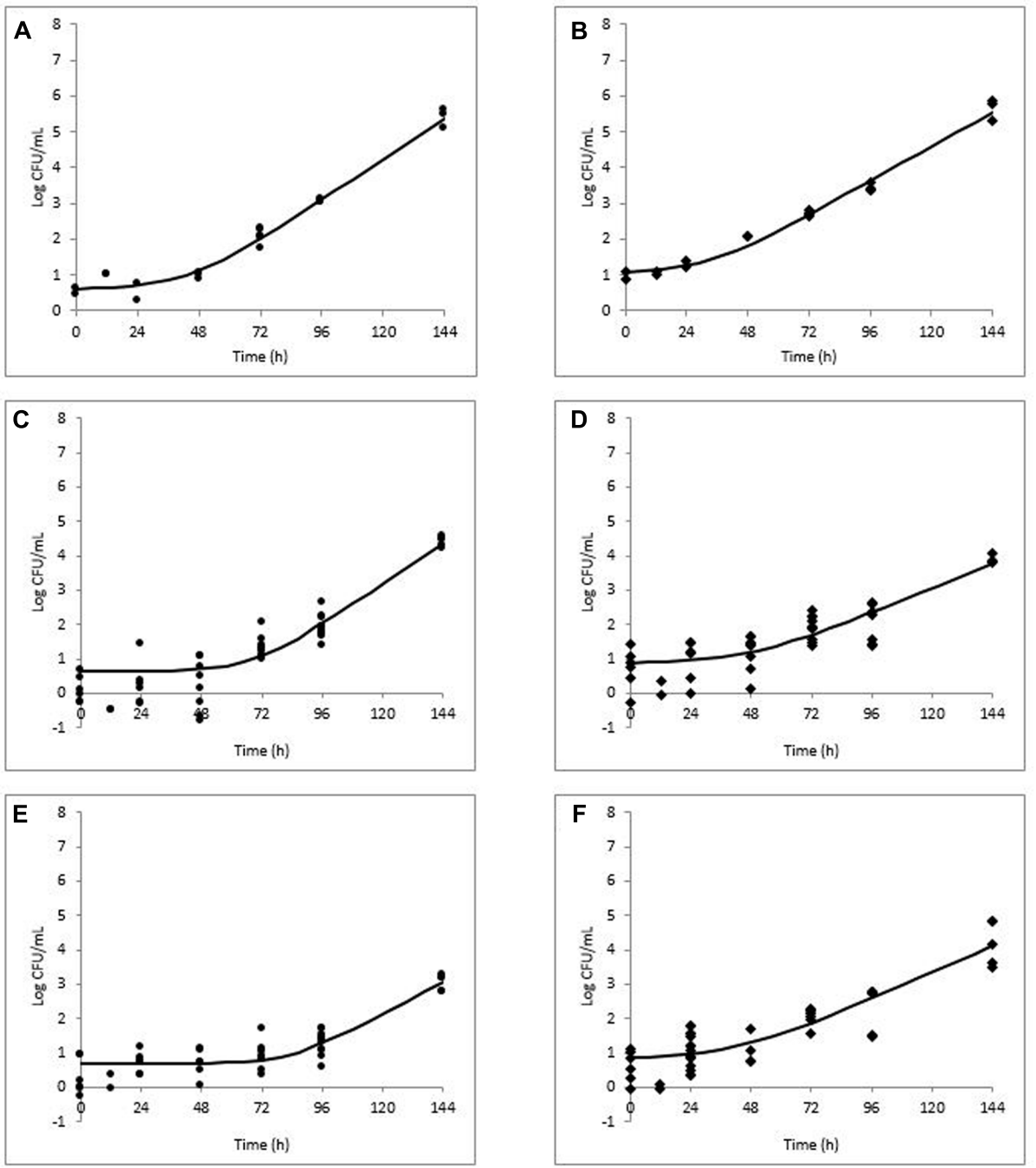

FIGURE 3 | Modeled growth of $L$. monocytogenes in milkshakes made from naturally and artificially contaminated ice cream with the addition of strawberry (A,B), chocolate (C,D), or mint (E,F) flavorings during storage at $10^{\circ} \mathrm{C}$ for $144 \mathrm{~h}$. Data points represent CFU per $\mathrm{mL}$ of milkshake. Line represents modeled growth. Circles (A,C,E) are naturally contaminated and diamonds (B,D,F) are artificially contaminated L. monocytogenes populations. 
In milkshakes supplemented with chocolate flavoring, the naturally contaminated L. monocytogenes had a significantly higher growth rate and maximum attained population after $144 \mathrm{~h}$ than the artificially contaminated condition. Lag phases of the pathogen in milkshakes with chocolate flavoring increased by approximately 21 and $35 \mathrm{~h}$ as compared with milkshakes without flavoring for the naturally and artificially contaminated conditions, respectively. An overall increase in population of only approximately 3.75 and $3.04 \log \mathrm{CFU} / \mathrm{mL}$ was observed by natural and artificial contamination states, respectively, after $144 \mathrm{~h}$ storage in milkshakes with chocolate flavoring.

In milkshakes with mint flavoring, the lowest growth rate was observed for the naturally contaminated L. monocytogenes; both contamination states also had the longest lag phases in mintflavored milkshakes, approximately 83 and $54 \mathrm{~h}$ for the naturally and artificially contaminated L. monocytogenes, respectively. After 144 h, approximately 1.92 and $3.53 \log \mathrm{CFU} / \mathrm{mL}$ increases in population were observed for the naturally and artificially contaminated L. monocytogenes, respectively, in milkshakes with mint flavoring.

Overall, the growth rates of both the naturally and artificially contaminated L. monocytogenes were significantly lower in milkshakes made with the tested flavoring agents than in those without flavoring. The greatest effect of the flavoring agents on L. monocytogenes, when taking into account all three kinetic parameters (growth rate, lag phase, and maximum population), was observed by mint, followed by chocolate, whereas the least effect was seen by strawberry. Regardless of flavoring addition or no addition, the naturally contaminated L. monocytogenes had higher growth rates and longer lag phases than the artificial counterpart.

\section{Secondary Modeling of Growth Rate and Lag Phase with Temperature}

The effect of storage temperature with L. monocytogenes growth rates and lag phases was modeled using the Ratkowsky equation (Ratkowsky et al., 1982) for $\mathrm{N}$ and A milkshakes (Figures 4A,B, respectively). Parameters and statistical analyses are presented in Table 3. Both derived models for comparing growth rate with temperature of the naturally and artificially contaminated L. monocytogenes in milkshakes presented with high $r^{2}$ values of

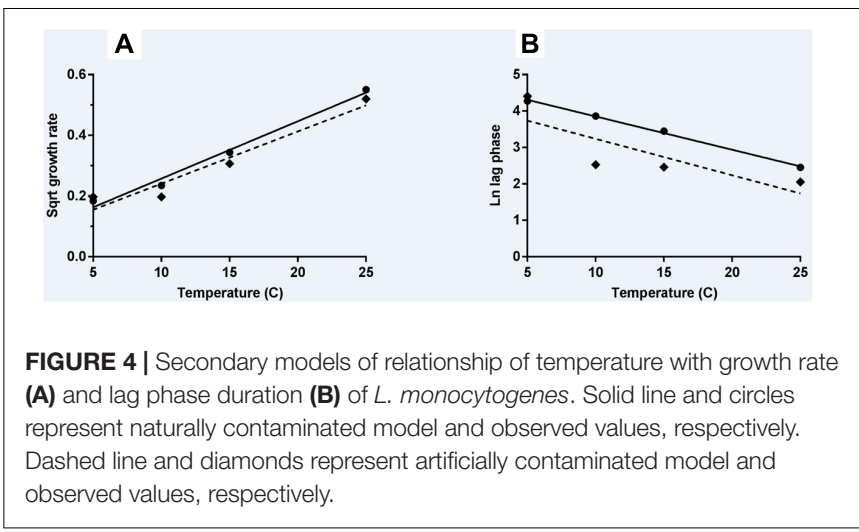

0.985 and 0.934 , respectively. The derived model for comparing lag phase with temperature for the naturally contaminated L. monocytogenes in milkshakes presented a high $r^{2}$ value of 0.997. However, the model for the artificially contaminated L. monocytogenes in milkshakes fit the Ratkowsky-type model poorly $\left(r^{2}=0.658\right)$ due to insignificant differences in lag phases when stored at 10 and $15^{\circ} \mathrm{C}$, indicating that the Ratkowsky-type model may not be the most accurate when assessing artificialcontamination.

\section{DISCUSSION}

This study assessed the growth dynamics of L. monocytogenes in milkshakes made from both artificially and naturally contaminated ice cream. A comparison of the behavior of natural vs. artificial contaminants in a food product has not been reported in the published literature. The naturally contaminated ice cream utilized in this research was uniformly contaminated with $10 \mathrm{MPN} / \mathrm{g}$ of L. monocytogenes (Chen, 2015); therefore, this inoculation level was used to inoculate artificially contaminated samples for experiments in this study to simulate a real-world situation.

For L. monocytogenes growth kinetics comparisons, four different contamination situations were assessed: naturally contaminated $(\mathrm{N})$, artificially contaminated (A, 4 strain

TABLE 3 | Parameters and statistical analyses of the derived secondary models for growth rate and lag phase for L. monocytogenes in milkshakes (A and N, see Figure 1) made with naturally and artificially contaminated ice cream.

\begin{tabular}{|c|c|c|c|c|c|}
\hline Kinetic parameter & $\begin{array}{l}\text { L. monocytogenes } \\
\text { condition }\end{array}$ & Model parameter & Estimated value $\pm S E$ & $P$ & $r^{2}$ \\
\hline \multirow[t]{4}{*}{$\mu_{\max }$} & Natural & $b$ & $0.019 \pm 0.002$ & 0.007 & 0.986 \\
\hline & & $T_{\min }\left({ }^{\circ} \mathrm{C}\right)$ & -3.638 & & \\
\hline & Artificial & b & $0.017 \pm 0.003$ & 0.033 & 0.934 \\
\hline & & $T_{\min }\left({ }^{\circ} \mathrm{C}\right)$ & -4.01 & & \\
\hline \multirow[t]{4}{*}{$\lambda$} & Natural & b & $-0.091 \pm 0.003$ & 0.001 & 0.997 \\
\hline & & $T_{\min }\left({ }^{\circ} \mathrm{C}\right)$ & 0.019 & & \\
\hline & Artificial & $b$ & $-0.101 \pm 0.06$ & 0.189 & 0.658 \\
\hline & & $T_{\min }\left({ }^{\circ} \mathrm{C}\right)$ & 0.024 & & \\
\hline
\end{tabular}

b, regression coefficient. $T_{\min }\left({ }^{\circ} \mathrm{C}\right)$, minimum extrapolated theoretical temperature for growth. Cl, confidence interval. ND, not determined. SE, standard error. 
cocktail), artificially contaminated (AJ, JKS-1 naturally contaminated strain), and 1.5-year cold adaptation of the artificially contaminated 4 strain cocktail (AC). Since the growth models developed in this study utilized $\mathrm{N}$ and $\mathrm{A}$ milkshakes, it was important to determine if the growth kinetics of $L$. monocytogenes would change under different situations (AJ and $\mathrm{AC}$ ). When growth rates of $\mathrm{AJ}$ and $\mathrm{AC} \mathrm{L}$. monocytogenes were compared against those of $\mathrm{A}$ at 10 and $25^{\circ} \mathrm{C}$ (Table 1), no differences were observed. This finding therefore reinforces the growth models developed in this study for L. monocytogenes in a milkshake matrix.

Research assessing the growth of L. monocytogenes in milkshakes made using the same naturally contaminated ice cream used in this study was conducted recently by Chen et al. (2016a). In their study, growth kinetics were compared in milkshakes made from the naturally contaminated ice cream with the addition of strawberry flavoring, chocolate flavoring, or no added flavoring. The milkshakes were stored at room temperature for $14 \mathrm{~h}$, with hourly sampling following a blending step. Results indicated that lag phases of the naturally contaminated L. monocytogenes were not significantly different for the strawberry, chocolate, or no added flavoring conditions. The current study utilized a much longer storage time $(144 \mathrm{~h})$ in order to determine predictive growth models for both the natural and artificial contaminant for risk assessment purposes. The current study also assessed a slightly higher concentration of flavoring in the milkshakes and also used UHT milk (see section Materials and Methods). These dissimilarities in experimental protocol could provide an explanation as to why significant differences in lag phases were observed in the current study between milkshakes with different flavorings.

Other similar studies have assessed L. monocytogenes growth in various dairy products although not in milkshakes. One study determined the growth kinetics of artificially inoculated L. monocytogenes in ice cream during storage at various cold and freezing temperatures (Gougouli et al., 2008). The study determined that growth rate of $L$. monocytogenes was significantly higher at $16^{\circ} \mathrm{C}$, as compared to $4^{\circ} \mathrm{C}$ storage, and that the maximum population density was not affected by storage temperature. The study also modeled the effect of temperature $\left(4,8,12\right.$, and $\left.16^{\circ} \mathrm{C}\right)$ on the growth rate of the pathogen in the ice cream samples using the Ratkowsky equation (Ratkowsky et al., 1982) and found $b$ and $T_{\min }$ parameters to be 0.0203 and -2.102 , respectively, similar to what was determined in the current study (Table 3) and other published studies (Alavi et al., 1999; Augustin et al., 2005; Xanthiakos et al., 2006). Another study which assessed the growth of artificially inoculated L. monocytogenes in pasteurized vanilla cream determined growth kinetics of the pathogen at storage temperatures of $3,5,10$, and $15^{\circ} \mathrm{C}$ (Panagou and Nychas, 2008). $b$ and $T_{\min }$ parameters were determined to be 0.017 and -6.30 , respectively, and these values are also similar to what was found in the current study.

Strawberry, chocolate, and mint flavorings were used in milkshakes in this study to determine if the addition of flavoring agents hindered the growth of the naturally or artificially contaminated L. monocytogenes. Results determined that the addition of flavoring to the milkshakes significantly lowered both the growth rates and the maximum attained populations of both the naturally and artificially contaminated L. monocytogenes during storage at $10^{\circ} \mathrm{C}$. Strawberries, along with other berries, are known to have antimicrobial properties (Puupponen-Pimiä et al., 2005; Nohynek et al., 2006). Previous research on strawberry puree and flavorings used in dairy products has determined that there are significant differences in pathogen growth in food products with and without the addition of strawberry (Canganella et al., 1998; Tirloni et al., 2015). For example, a study considering the fate of artificially inoculated L. monocytogenes and E. coli in strawberry flavored yogurt determined that bacterial loads were lower in the flavored yogurt as compared to that of the plain yogurt during storage at $4^{\circ} \mathrm{C}$ for 70 days (Tirloni et al., 2015).

Interestingly, L. monocytogenes has been reported to reach higher populations in dairy products containing chocolate than in those without (Rosenow and Marth, 1987a,b; Kenney and Beuchat, 2004). One study assessing the differences between growth of artificially inoculated L. monocytogenes in different milk products determined that the pathogen actually attained significantly higher maximum populations in chocolate milk than it did in whole or skim milk or cream after 70 days at $4^{\circ} \mathrm{C}$ storage (Rosenow and Marth, 1987b). Another study looking at the growth kinetics of whole-fat milk, whole-fat chocolate milk, and reduced-fat chocolate milk determined that artificially inoculated L. monocytogenes grew to higher population levels in both types of chocolate milk compared to the whole-fat milk during storage at $10^{\circ} \mathrm{C}$ for $96 \mathrm{~h}$ (Kenney and Beuchat, 2004). Although a decrease in both the growth rates and the maximum populations was observed in the current study, the divergence of the results stated here from the published literature may be due to variations in the formulation of the chocolate syrup used for flavoring the milkshakes in this study.

The addition of mint flavoring to the milkshakes in this study had the most significant effect on both naturally and artificially inoculated L. monocytogenes, resulting in reduced growth rates, lag phases, and maximum populations compared to the strawberry or chocolate flavorings. Mint has been shown to possess antimicrobial properties against L. monocytogenes (Irkin and Korukluoglu, 2009; Lixandru et al., 2010; Akdemir Evrendilek, 2015; Shahbazi, 2015). Only one study in the published literature has assessed the growth dynamics of L. monocytogenes in a dairy matrix with mint. Survival and growth of artificially inoculated $L$. monocytogenes was assessed in a yogurt drink in combination with mint and high pressure processing (Akdemir Evrendilek, 2015), and it was shown that the addition of mint to the yogurt drink significantly hindered the growth of L. monocytogenes, a conclusion which is also supported in this study.

This is the first report which compares the behavior of L. monocytogenes in naturally vs. artificially contaminated food product. In the comparison of both the naturally and artificially contaminated $L$. monocytogenes in the current study, there were significant differences in the growth of both contamination states in milkshakes; significant differences were also seen in the derived secondary models. The most significant difference 
was observed in the models relating lag phase to temperature (Figure 4B). The naturally contaminated L. monocytogenes was determined to have much longer lag phases than the artificially contaminated population in milkshakes stored between 5 and $25^{\circ} \mathrm{C}$. This difference in lag phases would ultimately determine the risk of this pathogen in milkshakes made from contaminated ice cream. Differences in natural and artificial contamination states should be considered when determining risk for ice cream and milkshakes.

\section{AUTHOR CONTRIBUTIONS}

JS, DS, and MT conceived and designed the experiments. JS, VB, CC, SN, AS, and DS performed the experiments. JS, VB, and CC analyzed the data. JS wrote the manuscript. CC, DS, and MT critically reviewed the manuscript.

\section{REFERENCES}

Akdemir Evrendilek, G. (2015). Empirical prediction and validation of antibacterial inhibitory effects of various plant essential oils on common pathogenic bacteria. Int. J. Food Microbiol. 202, 35-41. doi: 10.1016/j.ijfoodmicro.2015.02.030

Alavi, S. H., Puri, V. M., Knabel, S. J., Mohtar, R. H., and Whiting, R. C. (1999). Development and validation of a dynamic growth model for Listeria monocytogenes in fluid whole milk. J. Food Prot. 62, 170-176.

Augustin, J. C., Zuliani, V., Cornu, M., and Guillier, L. (2005). Growth rate and growth probability of Listeria monocytogenes in dairy, meat and seafood products in suboptimal conditions. J. Appl. Microbiol. 99, 1019-1042. doi: $10.1111 / j .1365-2672.2005 .02710 . x$

Baranyi, J., and Roberts, T. A. (1994). A dynamic approach to predicting bacterial growth in food. Int. J. Food Microbiol. 23, 277-294.

Beaufort, A., Rudelle, S., Gnanou-Besse, N., Toquin, M. T., Kerouanton, A., Bergis, H., et al. (2007). Prevalence and growth of Listeria monocytogenes in naturally contaminated cold-smoked salmon. Lett. Appl. Microbiol. 44, 406-411. doi: 10.1111/j.1472-765X.2006.02096.x

Briers, Y., Klumpp, J., Schuppler, M., and Loessner, M. J. (2011). Genome sequence of Listeria monocytogenes Scott A, a clinical isolate from a food-borne listeriosis outbreak. J. Bacteriol. 193, 4284-4285. doi: 10.1128/JB.05328-11

Canganella, F., Ovidi, M., Paganini, S., Vettraino, A. M., Bevilacqua, L., and Trovatelli, L. D. (1998). Survival of undesirable micro-organisms in fruit yoghurts during storage at different temperatures. Food Microbiol. 15, 71-77. doi: 10.1006/fmic.1997.0142

CDC (2015). Multistate Outbreak of Listeriosis Linked to Blue Bell Creameries Products (Final Update). Available at: http://www.cdc.gov/listeria/outbreaks/ ice-cream-03-15/ [accessed July 28, 2015].

Chen, Y. (2015). "Enumeration of Listeria monocytogenes in ice cream samples linked to a recent multi-state outbreak," in Proceedings of the Annual Meeting of International Association for Food Protection, Portland, OR.

Chen, Y., Allard, E., Wooten, A., Hur, M., Sheth, I., Laasri, A., et al. (2016a). Recovery and growth potential of Listeria monocytogenes in temperature abused milkshakes prepared from naturally contaminated ice cream linked to a listeriosis outbreak. Front. Microbiol. 7:764. doi: 10.3389/fmicb.2016. 00764

Chen, Y. I., Burall, L. S., Macarisin, D., Pouillot, R., Strain, E., De Jesus, A. J., et al. (2016b). Prevalence and level of Listeria monocytogenes in ice cream linked to a listeriosis outbreak in the United States. J. Food Prot. 79, 1828-1832. doi: 10.4315/0362-028X.JFP-16-208

Chen, Y., Gonzalez-Escalona, N., Hammack, T. S., Allard, M. W., Strain, E. A., and Brown, E. W. (2016c). Core genome multilocus sequence typing for identification of globally distributed clonal groups and differentiation of outbreak strains of Listeria monocytogenes. Appl. Environ. Microbiol. 82, 6258-6272. doi: 10.1128/AEM.01532-16

\section{FUNDING}

This work was supported in part by grant number U19FD005322 from the U.S. Food and Drug Administration to the Illinois Institute of Technology. JS and CC were supported by the Oak Ridge Institute for Science and Education Research Participation Program through a contract from the U.S. Food and Drug Administration.

\section{ACKNOWLEDGMENTS}

The authors would like to sincerely thank Dr. Yi Chen and Dr. Laurel Burall for helpful discussions. They also thank Karl Reineke for assistance with acquisition of the ice cream samples and Lauren Gonsalves, Vidya Natarajan, Tanvi Mhetras, and Chinmyee Sule for laboratory assistance.

Chen, Y., Luo, Y., Curry, P., Timme, R., Melka, D., Doyle, M., et al. (2017). Assessing the genome level diversity of Listeria monocytogenes from contaminated ice cream and environmental samples linked to a listeriosis outbreak in the United States. PLOS ONE 12:e0171389. doi: 10.1371/journal. pone. 0171389

Cortesi, M. L., Sarli, T., Santoro, A., Murru, N., and Pepe, T. (1997). Distribution and behavior of Listeria monocytogenes in three lots of naturally-contaminated vacuum-packed smoked salmon stored at 2 and 10 degrees C. Int. J. Food Microbiol. 37, 209-214.

Dalgaard, P., and Jørgensen, L. V. (1998). Predicted and observed growth of Listeria monocytogenes in seafood challenge tests and in naturally contaminated cold-smoked salmon. Int. J. Food Microbiol. 40, 105-115.

Dalton, C. B., Austin, C. C., Sobel, J., Hayes, P. S., Bibb, W. F., Graves, L. M., et al. (1997). An outbreak of gastroenteritis and fever due to Listeria monocytogenes in milk. N. Engl. J. Med. 336, 100-105. doi: 10.1056/NEJM199701093360204

Encinas, J. P., Sanz, J. J., García-López, M. L., and Otero, A. (1999). Behaviour of Listeria spp. in naturally contaminated chorizo (Spanish fermented sausage). Int. J. Food Microbiol. 46, 167-171.

Farber, J. M., and Daley, E. (1994). Presence and growth of Listeria monocytogenes in naturally-contaminated meats. Int. J. Food Microbiol. 22, 33-42.

FDA (2015). FDA Investigates Listeria Monocytogenes in Ice Cream Products from Blue Bell Creameries. Available at: http://wayback.archive-it.org/7993/ 20171114154904/https://www.fda.gov/Food/RecallsOutbreaksEmergencies/ Outbreaks/ucm 438104.htm [accessed July 28, 2015].

Fleming, D. W., Cochi, S. L., MacDonald, K. L., Brondum, J., Hayes, P. S., Plikaytis, B. D., et al. (1985). Pasteurized milk as a vehicle of infection in an outbreak of listeriosis. N. Engl. J. Med. 312, 404-407. doi: 10.1056/NEJM198502143120704

Gougouli, M., Angelidis, A. S., and Koutsoumanis, K. (2008). A study on the kinetic behavior of Listeria monocytogenes in ice cream stored under static and dynamic chilling and freezing conditions. J. Dairy Sci. 91, 523-530. doi: 10.3168 /jds.2007-0255

Hitchins, A. D., Jinneman, K., and Chen, Y. (2016). "Chapter 10: detection and enumeration of Listeria monocytogenes in foods," in Bacteriological Analytical Manual (Silver Spring, MD: FDA).

Irkin, R., and Korukluoglu, M. (2009). Growth inhibition of pathogenic bacteria and some yeasts by selected essential oils and survival of $L$. monocytogenes and C. albicans in apple-carrot juice. Foodborne Pathog. Dis. 6, 387-394. doi: $10.1089 /$ fpd.2008.0195

Jackson, E. E., Erten, E. S., Maddi, N., Graham, T. E., Larkin, J. W., Blodgett, R. J., et al. (2012). Detection and enumeration of four foodborne pathogens in raw commingled silo milk in the United States. J. Food Prot. 75, 1382-1393. doi: 10.4315/0362-028X.JFP-11-548

Jørgensen, L. V., and Huss, H. H. (1998). Prevalence and growth of Listeria monocytogenes in naturally contaminated seafood. Int. J. Food Microbiol. 42, $127-131$. 
Kenney, S. J., and Beuchat, L. R. (2004). Survival, growth, and thermal resistance of Listeria monocytogenes in products containing peanut and chocolate. J. Food Prot. 67, 2205-2211.

Lappi, V. R., Ho, A., Gall, K., and Wiedmann, M. (2004). Prevalence and growth of Listeria on naturally contaminated smoked salmon over 28 days of storage at 4 degrees C. J. Food Prot. 67, 1022-1026.

Linnan, M. J., Mascola, L., Lou, X. D., Goulet, V., May, S., Salminen, C., et al. (1988). Epidemic listeriosis associated with Mexican-style cheese. N. Engl. J. Med. 319, 823-828. doi: 10.1056/NEJM19880929319 1303

Lixandru, B. E., Drăcea, N. O., Dragomirescu, C. C., Drăgulescu, E. C., Coldea, I. L., Anton, L., et al. (2010). Antimicrobial activity of plant essential oils against bacterial and fungal species involved in food poisoning and/or food decay. Roum. Arch. Microbiol. Immunol. 69, 224-230.

Mejlholm, O., Bøknæs, N., and Dalgaard, P. (2015). Development and validation of a stochastic model for potential growth of Listeria monocytogenes in naturally contaminated lightly preserved seafood. Food Microbiol. 45(Pt B), 276-289. doi: $10.1016 /$ j.fm.2014.06.006

Nohynek, L. J., Alakomi, H. L., Kähkönen, M. P., Heinonen, M., Helander, I. M., Oksman-Caldentey, K. M., et al. (2006). Berry phenolics: antimicrobial properties and mechanisms of action against severe human pathogens. Nutr. Cancer 54, 18-32. doi: 10.1207/s15327914nc5401_4

Panagou, E. Z., and Nychas, G. J. (2008). Dynamic modeling of Listeria monocytogenes growth in pasteurized vanilla cream after postprocessing contamination. J. Food Prot. 71, 1828-1834.

Puupponen-Pimiä, R., Nohynek, L., Hartmann-Schmidlin, S., Kähkönen, M., Heinonen, M., Määttä-Riihinen, K., et al. (2005). Berry phenolics selectively inhibit the growth of intestinal pathogens. J. Appl. Microbiol. 98, 991-1000. doi: 10.1111/j.1365-2672.2005.02547.x

Ratkowsky, D. A., Olley, J., McMeekin, T. A., and Ball, A. (1982). Relationship between temperature and growth rate of bacterial cultures. J. Bacteriol. $149,1-5$.
Rosenow, E. M., and Marth, E. H. (1987a). Addition of cocoa powder, cane sugar, and carrageenan to milk enhances growth of Listeria monocytogenes. J. Food Prot. 50, 576-579. doi: 10.4315/0362-028X-50.9.726

Rosenow, E. M., and Marth, E. H. (1987b). Growth of Listeria monocytogenes in skim, whole and chocolate milk, and in whipping cream during incubation at 4 , 8, 13, 21, and 35C. J. Food Prot. 50, 452-459. doi: 10.4315/0362-028X-50.6.452

Ryser, E. T., Arimi, S. M., Bunduki, M. M., and Donnelly, C. W. (1996). Recovery of different Listeria ribotypes from naturally contaminated, raw refrigerated meat and poultry products with two primary enrichment media. Appl. Environ. Microbiol. 62, 1781-1787.

Shahbazi, Y. (2015). Chemical composition and In Vitro antibacterial activity of Mentha spicata essential oil against common food-borne pathogenic bacteria. J. Pathog. 2015:916305. doi: 10.1155/2015/916305

Tirloni, E., Bernardi, C., Colombo, F., and Stella, S. (2015). Microbiological shelf life at different temperatures and fate of Listeria monocytogenes and Escherichia coli inoculated in unflavored and strawberry yogurts. J. Dairy Sci. 98, 4318-4327. doi: 10.3168/jds.2015-9391

Xanthiakos, K., Simos, D., Angelidis, A. S., Nychas, G. J., and Koutsoumanis, K. (2006). Dynamic modeling of Listeria monocytogenes growth in pasteurized milk. J. Appl. Microbiol. 100, 1289-1298. doi: 10.1111/j.1365-2672.2006.02854.x

Conflict of Interest Statement: The authors declare that the research was conducted in the absence of any commercial or financial relationships that could be construed as a potential conflict of interest.

Copyright (c) 2018 Salazar, Bathija, Carstens, Narula, Shazer, Stewart and Tortorello. This is an open-access article distributed under the terms of the Creative Commons Attribution License (CC BY). The use, distribution or reproduction in other forums is permitted, provided the original author(s) or licensor are credited and that the original publication in this journal is cited, in accordance with accepted academic practice. No use, distribution or reproduction is permitted which does not comply with these terms. 